\title{
Induction with sevoflurane-remifentanil is compa- rable to propofol-fentanyl-rocuronium in PONV after laparoscopic surgery
}

\author{
[L'induction avec sévoflurane-rémifentanil ou propofol-fentanyl-rocuronium est \\ similaire quant aux NVPO en chirurgie laparoscopique]
}

Homer Yang MD FRCPC, ${ }^{*}$ Peter T.-L. Choi MD FRCPC, $†$ James McChesney MB CHB FRCPC, $\dagger$ Norman Buckley MD FRCPC*

Purpose: To compare sevoflurane-remifentanil induction and propofol-fentanyl-rocuronium induction with regards to the frequency of moderate to severe postoperative nausea and vomiting (PONV) in the first $24 \mathrm{hr}$ after laparoscopic day surgery.

Methods: After informed consent, I 56 ASA physical status class I to III patients undergoing laparoscopic cholecystectomy or tubal ligation were randomized to either induction with sevoflurane $8 \%, \mathrm{~N}_{2} \mathrm{O}$ $67 \%$ and iv remifentanil I to $1.5 \mu \mathrm{g} \cdot \mathrm{kg}^{-1}$ or induction with iv fentanyl 2 to $3 \mu \mathrm{g} \cdot \mathrm{kg}^{-1}$, propofol $2 \mathrm{mg} \cdot \mathrm{kg}^{-1}$, and rocuronium 0.3 to 0.5 $\mathrm{mg} \cdot \mathrm{kg}^{-1}$. All patients received iv ketorolac $0.5 \mathrm{mg} \cdot \mathrm{kg}^{-1}$ at induction and sevoflurane- $\mathrm{N}_{2} \mathrm{O}$ maintenance anesthesia with rocuronium as needed. PONV was treated with iv ondansetron, droperidol, or dimenhydrinate; postoperative pain was treated with opioid analgesics. Patients were followed for $24 \mathrm{hr}$ with regards to PONV and pain. Intubating conditions, induction and emergence times, time to achieve fast-track discharge criteria, and drug costs were measured.

Results: No differences were seen between the two groups in their frequencies of 24-hr moderate to severe PONV and postoperative pain, or in their intubating conditions, induction and emergence times, and time to achieve fast-track discharge criteria. Patients undergoing sevoflurane-remifentanil induction received more morphine ( I I mg vs $8 \mathrm{mg} ; P<0.00 \mathrm{I}$ ) in the postanesthetic care unit. Sevoflurane-remifentanil induction resulted in similar anesthetic and total drug costs for both procedures.

Conclusion: We did not demonstrate any difference in PONV, pain, or anesthetic/recovery times or costs between the sevoflurane and propofol groups. Sevoflurane-remifentanil induction is a feasible technique for anesthetic induction.
Objectif : Comparer l'induction avec sévoflurane-rémifentanil ou propofol-fentanyl-rocuronium quant à la fréquence de nausées et vomissements postopératoires (NVPO) de modérés à sévères pendant les 24 premières heures après une opération en chirurgie d'un jour sous laparoscopie.

Méthode : Après avoir accordé leur consentement, 156 patients d'état physique ASA I à III devant subir une cholécystectomie laparoscopique ou une ligature des trompes ont été randomisés pour une induction avec du sévoflurane à $8 \%, \mathrm{~N}_{2} \mathrm{O}$ à $67 \%$ et I à I,5 $\mu \mathrm{g} \cdot \mathrm{kg}^{-1}$ de rémifentanil iv ou une induction iv avec 2 à $3 \mu \mathrm{g} \cdot \mathrm{kg}^{-1}$ de fentanyl, $2 \mathrm{mg} \cdot \mathrm{kg}^{-1}$ de propofol et 0,3 à $0,5 \mathrm{mg} \cdot \mathrm{kg}^{-1}$ de rocuronium. Tous les patients ont reçu $0,5 \mathrm{mg} \cdot \mathrm{kg}^{-1}$ de kétorolac iv à l'induction et un mélange de sévoflurane$\mathrm{N}_{2} \mathrm{O}$ pour le maintien de l'anesthésie, avec rocuronium au besoin. Un traitement iv avec ondansétron, dropéridol ou dimenhydrinate a été donné pour les NVPO et la douleur postopératoire a été soulagée avec des analgésiques opioïdes. Les patients ont été suivis pendant $24 \mathrm{~h}$ pour les NVPO et la douleur. Ont été notés : les conditions d'intubation, les temps nécessaires à l'induction et au réveil, le temps d'atteindre les critères de congé de la chirurgie ambulatoire et le coût des médicaments.

Résultats : Aucune différence intergroupe n'a été enregistrée concernant la fréquence de NVPO de modérés à sévères et la douleur postopératoire pendant $24 \mathrm{~h}$, ou les conditions d'intubation, les temps d'induction et de réveil, de même que le temps nécessaire à l'atteinte des critères de congé. Les patients soumis à une induction avec un mélange de sévoflurane-rémifentanil ont demandé plus de morphine ( I I mg vs $8 \mathrm{mg} ; P<0,00$ I) en salle de réveil. L'induction avec sévoflurane-rémifentanil a conduit à un usage d'anesthésiques et à un

From the Departments of Anesthesia, Hamilton Health Sciences, ${ }^{*}$ and St. Joseph's Healthcare; $\dagger$ and the Department of Clinical Epidemiology \& Biostatistics, $\ddagger$ McMaster University, Hamilton, Ontario, Canada.

Address correspondence to: Dr. Norman Buckley, McMaster University, Department of Anesthesia, 1200 Main Street West, Room HSC2U1, Hamilton, Ontario L8N 3Z5, Canada. Phone: 905-521-2100, ext. 75166; Fax: 905-523-1224; E-mail: buckleyn@mcmaster.ca Dr. Yang is now with the Department of Anesthesia, University of Ottawa; Dr. Choi is now with the Vancouver Coastal Health Research Institute and the Department of Anesthesia, University of British Columbia.

This study was supported in part by a grant from Abbott Laboratories Ltd.

Competing interests: none declared.

Accepted for publication September 5, 2003.

Revision accepted April 14, 2004. 
coût total de médicaments similaires pour les deux types d'interventions chirurgicales.

Conclusion : Nous n'avons trouvé aucune différence de NVPO, de douleur ou de temps liés à l'analgésie et à la récupération postopératoires entre les groupes sous sévoflurane ou propofol. Un mélange de sévoflurane-rémifentanil peut servir à l'induction de l'anesthésie.

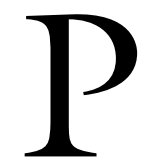

OSTOPERATIVE nausea and vomiting (PONV) remains an important and frequent complication following surgery and anesthesia. In the ambulatory setting, PONV is one of the most significant factors predicting prolonged postoperative stay and unanticipated admissions. ${ }^{1,2}$ Additionally, PONV is a strong negative influence upon a patient's postoperative function ${ }^{3}$ and satisfaction. ${ }^{4}$

The frequency of PONV in the ambulatory setting varies significantly, depending on the type of surgery, patient characteristics, and type of anesthesia. For patients undergoing minor gynecological surgery, the risk of nausea and vomiting is $75 \%$ and $61 \%$ respectively. ${ }^{5}$ In laparoscopic cholecystectomy, the frequency (without prophylactic antiemetics) was reported to be $72 \%$ in one randomized controlled trial. ${ }^{6}$ In the presence of prophylactic antiemetics, the frequency decreased, but remained significant, within a range of $30 \%$ to $60 \%$ depending on the type of study. ${ }^{7-9}$ Female gender, history of motion sickness or PONV, and a negative smoking history are also risk factors for PONV. ${ }^{1,3}$ In general, these characteristics are not amenable to modification in the preoperative setting.

A number of anesthetic factors may influence the risk of PONV. Omission of $\mathrm{N}_{2} \mathrm{O}$ significantly reduced PONV in several meta-analyses, ${ }^{10-13}$ but the risk of intraoperative awareness was also increased. ${ }^{12}$ In most meta-analyses, propofol was associated with a lower frequency of PONV when used for total $i v$ anesthesia in the absence of $\mathrm{N}_{2} \mathrm{O} \cdot{ }^{12-15}$ In one meta-analysis, the rate of PONV was lower with the use of any propofol when compared with sevoflurane. ${ }^{16}$ The omission of anticholinesterases (for reversal of muscle relaxation) also reduced PONV but also resulted in an increased risk of clinically relevant residual muscle weakness. ${ }^{17}$ Postoperative use of opioid analgesics was also associated with an increased frequency of PONV.

Ideally, for general anesthesia in the ambulatory laparoscopic population, one would choose an agent with rapid onset and elimination that would provide adequate amnesia and muscle relaxation for the surgical procedure. For analgesia in mild to moderately painful procedures, if opioids are needed, the agent should also have rapid onset and elimination. Postoperative analgesia would then be achieved via non-opioid analgesics, such as nonsteroidal antiinflammatory drugs, with longer lasting opioids used for breakthrough pain.

The desired properties of a general anesthetic, as highlighted above, may be achieved with sevoflurane and remifentanil. The use of sevoflurane as the sole anesthetic agent for induction and maintenance provides adequate intubating conditions without the use of muscle relaxants. Numerous reports have also demonstrated similar intubating conditions, in the absence of muscle relaxants, using remifentanil and propofol as the co-induction agents. ${ }^{18-24}$ Recently, induction with remifentanil and sevoflurane has enabled rapid endotracheal intubation without the use of muscle relaxants. ${ }^{25}$

What remained to be seen was whether sevoflurane-remifentanil induction, a novel technique, would decrease the frequency of PONV compared to standard practice. The primary objective of this study was to determine the frequency of PONV with the use of sevoflurane-remifentanil induction compared to propofol-fentanyl-rocuronium induction in ambulatory patients undergoing laparoscopic surgery.

\section{Methods}

This study was conducted in two tertiary care, academic hospitals (Hamilton Health Sciences - McMaster site and St. Joseph's Hospital) in Hamilton, Ontario. After Institutional Research Ethics Board approval and informed consent, we enrolled patients undergoing laparoscopic cholecystectomy or laparoscopic tubal ligation ${ }^{\mathrm{A}}$ who met the following criteria: weight $\leq 100 \mathrm{~kg}$, body mass index $\leq 35 \mathrm{~kg} \cdot \mathrm{m}^{-2}$, age $>16 \mathrm{yr}$, ASA physical status class $\leq$ III, and elective procedure booked for same-day discharge. Patients were excluded if they had participated in another study with an experimental drug within the month prior to enrollment, were pregnant or breastfeeding, had received medications with anti-emetic properties within $48 \mathrm{hr}$ of surgery, or had contraindications to the anesthetic techniques or the medications used in this study.

Using a random numbers table, stratified by centre and procedure, patients were allocated, upon entry into the operating room, to sevoflurane-remifentanil induction (sevoflurane group) or propofol-fentanylrocuronium induction (propofol group). The anesthesiologists and operating room nurses were not blinded

A Laparoscopic tubal ligations were performed at the Hamilton Health Sciences only. 
but patients were not informed of the induction technique that they received. A restricted group of 12 anesthesiologists, competent in the sevofluraneremifentanil induction technique, performed all the anesthetics to ensure consistency. We did not exclude any general surgeon or gynecologist from participating nor did we control the laparoscopic techniques used. The surgical team was blinded to the induction technique. The postoperative data collectors and the data analysts were blinded to the intervention.

In the sevoflurane group, a vital capacity induction technique (sevoflurane $8 \%, \mathrm{~N}_{2} \mathrm{O} 2 \mathrm{~L} \cdot \mathrm{min}^{-1}, \mathrm{O}_{2} \mathrm{l}$ $\mathrm{L} \cdot \mathrm{min}^{-1}$ ) was used to obtain loss of consciousness, followed by a 30 -sec $i v$ injection of remifentanil 1 to 1.5 $\mu \mathrm{g} \cdot \mathrm{kg}^{-1}$. One minute after remifentanil administration, tracheal intubation was attempted. Sevoflurane and additional boluses of remifentanil $0.5 \mu \mathrm{g} \cdot \mathrm{kg}^{-1} i v$ were used to maintain anesthesia until intubation was successful. Once the trachea was intubated, anesthesia was maintained with $\mathrm{N}_{2} \mathrm{O} 1.3 \mathrm{~L} \cdot \mathrm{min}^{-1}, \mathrm{O}_{2} 0.7 \mathrm{~L} \cdot \mathrm{min}^{-1}$, and sevoflurane as per the anesthesiologist. Rocuronium $0.15 \mathrm{mg} \cdot \mathrm{kg}^{-1} i v$ was used if muscle relaxation was inadequate with sevoflurane alone. Remifentanil was not administered after endotracheal intubation.

In the propofol group, patients received fentanyl 2 to $3 \mu \mathrm{g} \cdot \mathrm{kg}^{-1}$ iv one minute prior to induction, followed by propofol $2 \mathrm{mg} \cdot \mathrm{kg}^{-1}$ iv and rocuronium 0.3 to $0.5 \mathrm{mg} \cdot \mathrm{kg}^{-1}$ iv for induction. One minute later, tracheal intubation was attempted. Additional boluses of propofol $\mathrm{l} \mathrm{mg} \cdot \mathrm{kg}^{-1}$ iv or fentanyl $\mathrm{l}$ to $2 \mu \mathrm{g} \cdot \mathrm{kg}^{-1}$ iv were given as needed until the trachea could be intubated. Anesthesia was maintained with $\mathrm{N}_{2} \mathrm{O} \quad 1.3$ $\mathrm{L} \cdot \mathrm{min}^{-1}, \mathrm{O}_{2} 0.7 \mathrm{~L} \cdot \mathrm{min}^{-1}$, and sevoflurane as per the anesthesiologist. Supplemental boluses of fentanyl 1 to $2 \mu \mathrm{g} \cdot \mathrm{kg}^{-1}$ iv were given as needed for analgesia at the discretion of the patient's anesthesiologist based on clinical signs and symptoms (e.g., tachycardia, hypertension, pupillary dilatation). Supplemental boluses of rocuronium $0.15 \mathrm{mg} \cdot \mathrm{kg}^{-1}$ iv were given as needed for muscle relaxation based on neuromuscular train-of-four monitoring.
No patient received any prophylactic anti-emetic, analgesic, or anxiolytic. In both groups, ketorolac 0.5 $\mathrm{mg} \cdot \mathrm{kg}^{-1}$ (maximum $30 \mathrm{mg}$ ) iv was given for pre-emptive analgesia at induction. In patients who received rocuronium, reversal of neuromuscular blockade was achieved with neostigmine 30 to $50 \mu \mathrm{g} \cdot \mathrm{kg}^{-1}$ iv and glycopyrrolate 5 to $8 \mu \mathrm{g} \cdot \mathrm{kg}^{-1} i \mathrm{iv}$. Anesthesia was terminated at the end of the surgery.

In the postanesthetic care unit, patients received morphine 2 to $4 \mathrm{mg} i v$ every five minutes, to a maximum total dose of $0.3 \mathrm{mg} \cdot \mathrm{kg}^{-1}$, as needed for analgesia. Meperidine 25 to $50 \mathrm{mg}$ iv every $15 \mathrm{~min}$, to a maximum total dose of $1 \mathrm{mg} \cdot \mathrm{kg}^{-1}$, was used as the second-line analgesic. PONV was treated with droperidol $25 \mu \mathrm{g} \cdot \mathrm{kg}^{-1}$ iv or ondansetron $4 \mathrm{mg} i v$. During this study, Health Canada released a bulletin concerning potential cardiac complications with the use of droperidol. ${ }^{26}$ At that point, the use of droperidol was discontinued and ondansetron was used as the firstline rescue anti-emetic. Dimenhydrinate 0.25 to 0.5 $\mathrm{mg} \cdot \mathrm{kg}^{-1} i v$ was used as the second-line rescue antiemetic. For postdischarge analgesia, prescriptions for Tylenol \#2 (acetaminophen $325 \mathrm{mg} /$ codeine $20 \mathrm{mg}$ ) tablets and Tylenol \#3 (acetaminophen 325 $\mathrm{mg} /$ codeine $30 \mathrm{mg}$ ) tablets were given to patients after laparoscopic cholecystectomy and laparoscopic tubal ligation respectively.

\section{Measurements and statistical analysis}

The primary outcome of this study was the frequency of moderate to severe PONV over the first $24 \mathrm{hr}$ after surgery. Severity of PONV was measured using a 10$\mathrm{cm}$ visual analogue scale (VAS) with scores greater than 3 considered to be moderate to severe. Secondary outcomes included moderate to severe pain over the first $24 \mathrm{hr}$ after surgery (measured using a 10$\mathrm{cm}$ VAS similar to PONV measurements), ease of intubation (measured using a six-item, 12-point score, Table I), anesthetic induction and emergence times, time required to achieve fast-track criteria, ${ }^{27}$ amount of postoperative anti-emetics and analgesics used, and total drug costs. Intraoperative data were recorded by

TABLE I Factors evaluated to determine ease of intubation. Intubating score is based on the consensus conference on good clinical research practice in pharmacodynamic studies of neuromuscular blocking agents ${ }^{32}$

\begin{tabular}{lll}
\hline Factor & 0 point & 1 point \\
\hline Manual ventilation prior to intubation & Easily ventilated & Some difficulty \\
Jaw relaxation & Relaxed & Opens with some difficulty $\quad$ Opens with great difficulty \\
Ease of laryngoscopy & Easy & Some difficulty \\
Vocal cords & Open without movement & Some movement \\
Coughing during intubation & None & $\leq 2$ coughs \\
Limb movement & None & Flicker of movement \\
\hline
\end{tabular}




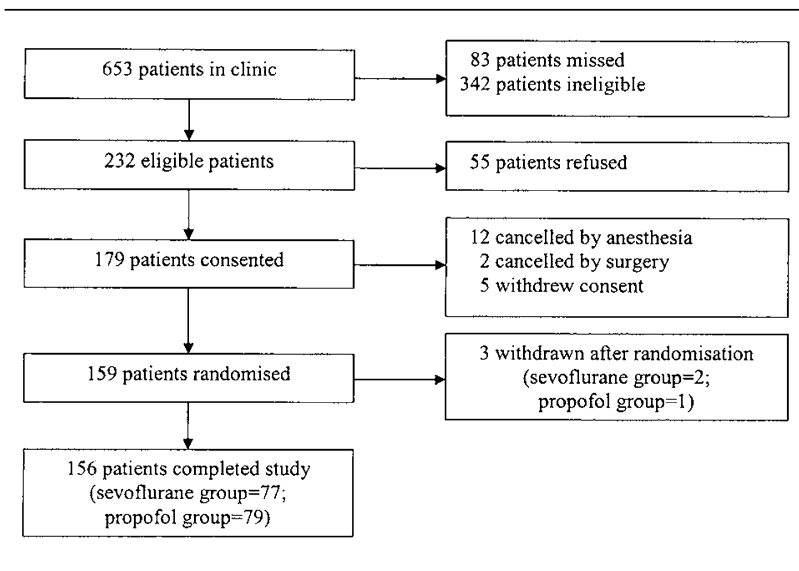

FIGURE 1 Summary of trial profile.

the patient's anesthesiologist; postoperative data were measured by a blinded research assistant. To determine drug costs, we assumed that leftover medications from a case would be thrown out at the end of the case with the exception of remifentanil, in which the required dose would be drawn from a premixed bag ( $1 \mathrm{mg}$ in $100 \mathrm{~mL}$ of normal saline), which was the clinical practice at the time of the study. Similarly, we assumed that leftover anti-emetics or analgesics would be discarded in the postoperative period in hospital.

Sample size calculation was based on an expected frequency of $60 \%$ for moderate to severe PONV in the propofol group, $27 \%$ absolute risk reduction (45\% relative risk reduction), a $5 \%$ two-sided type I error rate, and $90 \%$ power. After accounting for stratification by centre and surgical procedure and an anticipated 5\% withdrawal rate, 78 patients per group were required. A power analysis indicated that this sample size would detect an absolute difference of $23.5 \%$ with $80 \%$ power and an absolute difference of $21 \%$ with $70 \%$ power.

The Mantel-Haenszel Chi-square statistic was used to compare the two groups for the primary outcome with the results expressed as proportions and odds ratios (OR) with 95\% confidence intervals (CI). A multivariate analysis was conducted to determine the effect of PONV risk factors, ${ }^{28}$ surgical procedure, and study centre on PONV. The primary analysis was adjusted for those factors that were found to be statistically significant in the multivariate analysis. A $P$ value $<0.05$ was considered to be statistically significant for the primary outcome.

For secondary outcomes, dichotomous data were expressed as proportions and OR with 95\% CI and were compared using the Chi-square statistic or
Fisher's exact test where appropriate. Normally distributed, continuous data were expressed as means and standard deviations and were compared using the two-sided $t$ test. Non-normally distributed, continuous data were expressed as medians and were compared using the Wilcoxon rank sum test. Given the multiple comparisons, a Bonferroni correction was made; a $P$ value of $<0.005$ was considered statistically significant.

The investigators, including the anesthesiologists, pharmacists, and research nurses were presented with the blinded results, as "Group A" and "Group B," for interpretation. The group allocations were unmasked only after the interpretation was completed. Because between-group comparisons of the amounts and costs of individual intraoperative drugs would unmask the allocation and unblind the data analyst, we did not make any comparisons of specific drug amounts or costs during the initial blinded analysis. Post hoc unblinded analyses of the costs for specific drugs were made.

\section{Results}

Figure 1 summarizes the trial profile. One hundred and fifty-nine patients were randomized during the study; however, one patient had clinical signs strongly predictive of a difficult intubation, which was missed during the preoperative assessment clinic visit but detected prior to induction, one patient had severe nausea prior to induction, and one patient did not undergo the scheduled procedure. In total, 156 patients completed the study. There were no statistically significant differences in the physical characteristics or the distribution of PONV risk factors between the two groups (Table II).

The number of PONV risk factors was a significant predictor of PONV but the number of days after menses, in menstruating women, was not. The overall frequency of moderate to severe PONV over $24 \mathrm{hr}$ was high (44.8\%); however, the frequency in the sevoflurane group $(41 / 77 ; 53.2 \%)$ was not significantly different from the frequency in the propofol group $(29 / 79 ; 36.7 \%)$ with an OR, adjusted for the number of PONV risk factors, of 1.79 (95\% CI 0.92 to $3.38 ; P=0.12$ ). There were no significant differences in the frequency of moderate to severe PONV over $24 \mathrm{hr}$ between the two anesthetic techniques in the laparoscopic cholecystectomy and laparoscopic tubal ligation subgroups.

The frequency of moderate to severe postoperative pain over $24 \mathrm{hr}$ was not significantly different between the sevoflurane $(70 / 77 ; 90.9 \%)$ and the propofol $(66 / 79 ; 83.5 \%)$ groups (OR 1.97; 95\% CI 0.74 to 5.24; $P=0.26)$. The number of PONV risk factors, 
TABLE II Physical characteristics and distribution of postoperative nausea and vomiting risk factors between groups

\begin{tabular}{|c|c|c|}
\hline Characteristic* & $\begin{array}{l}\text { Sevoflurane group } \\
(n=79)\end{array}$ & $\begin{array}{l}\text { Propofol group } \\
(n=80)\end{array}$ \\
\hline Age (yr) & $37.5 \pm 11.1$ & $38.7 \pm 10.9$ \\
\hline Height $(\mathrm{cm})$ & $161.7 \pm 19.2$ & $166.1 \pm 8.0$ \\
\hline Weight $(\mathrm{kg})$ & $68.6 \pm 14.3$ & $72.3 \pm 13.2$ \\
\hline \multicolumn{3}{|l|}{ PONV risk factors } \\
\hline Female $(\%)$ & $72(91.1)$ & $68(85.0)$ \\
\hline Motion sickness (\%) & $21(26.6)$ & $10(12.5)$ \\
\hline PONV (\%) & $27(34.2)$ & $23(28.8)$ \\
\hline Non-smoking status (\%) & $25(31.6)$ & $31(38.8)$ \\
\hline Number of risk factors $(0 / 1 / 2 / 3) \dagger$ & $0 / 17 / 35 / 26$ & $5 / 21 / 39 / 15$ \\
\hline \multicolumn{3}{|c|}{ Time in menstrual cycle } \\
\hline 0 to 8 days after menses (\%) & $20(27.8)$ & $17(25.0)$ \\
\hline 9 to 16 days after menses (\%) & $11(15.3)$ & $14(20.6)$ \\
\hline$>16$ days after menses $(\%)$ & $26(36.1)$ & $20(29.4)$ \\
\hline On hormone replacement (\%) & $2(2.8)$ & $5(7.4)$ \\
\hline Post-menopausal (\%) & $10(13.9)$ & $8(11.8)$ \\
\hline Unclear (\%) & $3(4.2)$ & $4(5.9)$ \\
\hline Laparoscopic cholecystectomy & $32(41.6)$ & $35(44.3)$ \\
\hline Laparoscopic tubal ligation & $45(58.4)$ & $44(55.7)$ \\
\hline
\end{tabular}

${ }^{*}$ Continuous variables are expressed as means \pm standard deviations; discrete variables are expressed as absolute number and percentages. $†$ Motion sickness or postoperative nausea and vomiting (PONV) were counted as one risk factor.

the number of days after menses, and the surgical procedure did not affect the result. No adverse events were seen resulting from anesthesia.

Intubating conditions were not significantly different between the two anesthetic techniques (Figure 2). Induction times (sevoflurane $3.4 \pm 2.2 \mathrm{~min}$ vs propofol $3.2 \pm 3.0 \mathrm{~min} ; P=0.49$ ) and emergence times (sevoflurane $4.2 \pm 2.4 \mathrm{~min} v s$ propofol $4.5 \pm 2.0 \mathrm{~min}$; $P=0.39)$ were not significantly different between the two groups. Time to reach fast-track discharge criteria was not significantly different (Figure $3 ; P=0.08$ ) with a median time of 45 min for both groups; however, discharge from the postanesthetic care unit was often delayed due to non-medical factors. The type of surgery did not affect these findings.

The amounts of anti-emetics, meperidine, and acetaminophen-codeine used per patient in the postanesthetic care unit, in hospital, and during $24 \mathrm{hr}$ were not significantly different between the two groups. The amount of morphine used was higher in the sevoflurane group $(11 \mathrm{mg})$ than in the propofol group ( $8 \mathrm{mg} ; P<0.001)$ in the postanesthetic care unit. Sevoflurane-remifentanil induction followed by sevoflurane maintenance anesthesia was comparable to propofol-fentanyl-rocuronium induction followed by sevoflurane maintenance anesthesia (\$34.21 vs

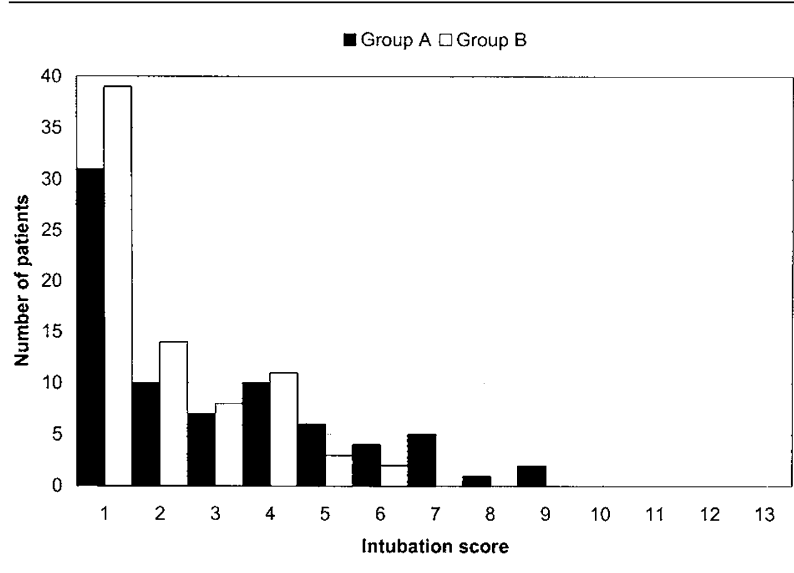

FIGURE 2 Bar chart of intubation scores by type of anesthetic induction. Group A = sevoflurane group; Group B = propofol group.

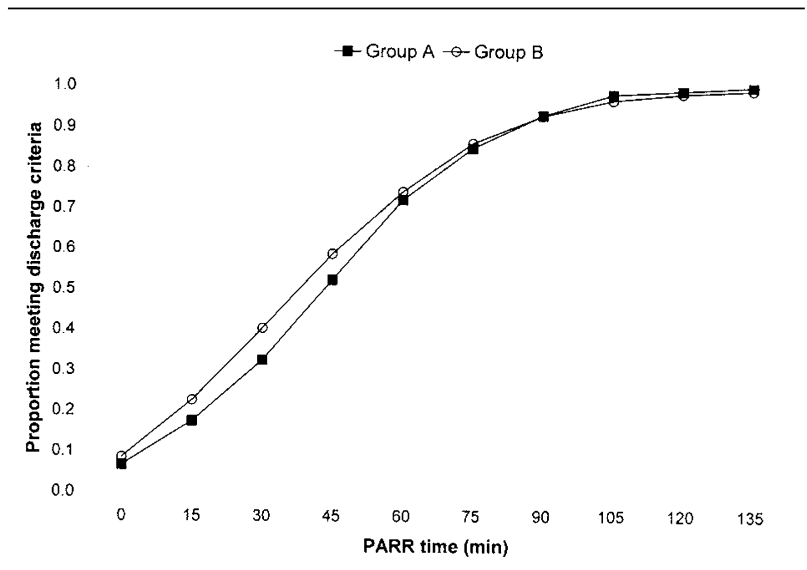

FIGURE 3 Kaplan-Meier plot of fast-track discharge eligibility over time by type of anesthetic induction. Group A = sevoflurane group; Group B = propofol group.

$\$ 38.29 ; P=0.089)$ and did not significantly increase the costs of postoperative anti-emetic and analgesic use (sevoflurane group $\$ 25.72$ vs propofol group $\$ 17.27 ; P=0.028)$. The difference in intraoperative anesthetic drug costs was not statistically significant for either types of surgery (Table III). Overall, the total drug cost in the sevoflurane group was not significantly different from the propofol group $(\$ 56.81$ vs $\$ 46.78 ; P=0.045)$. 
TABLE III Drug costs by type of anesthetic and surgery

\begin{tabular}{llll}
\hline & Sevoflurane group & Propofol group & Difference $\left(95 \%\right.$ CI) $^{*}$ \\
\hline $\begin{array}{l}\text { Intraoperative drug costs } \\
\text { All patients }\end{array} \quad \$ 34.21$ & & $\$ 38.29$ & $\$ 4.08(-\$ 0.63$ to $\$ 8.80)$ \\
$\quad$ Sevoflurane & $\$ 23.84$ & $\$ 10.39$ & $-\$ 13.45(-\$ 17.12$ to $-\$ 9.78) \dagger$ \\
$\quad$ Intraoperative opioids $\ddagger$ & $\$ 1.19$ & $\$ 0.82$ & $-\$ 0.38(-\$ 0.50$ to $-\$ 0.24) \dagger$ \\
$\quad$ Rocuronium & $\$ 4.41$ & $\$ 13.07$ & $\$ 8.66(\$ 7.08$ to $\$ 10.23) \dagger$ \\
$\quad$ Neostigmine and glycopyrrolate & $\$ 1.70$ & $\$ 6.24$ & $\$ 4.54(\$ 3.87$ to $\$ 5.21) \dagger$ \\
Laparoscopic cholecystectomy & $\$ 47.65$ & $\$ 44.71$ & $-\$ 2.94(-\$ 10.35$ to $\$ 4.48)$ \\
Laparoscopic tubal ligation & $\$ 24.65$ & $\$ 33.18$ & $\$ 8.53(\$ 4.83$ to $\$ 12.24)$ \\
Postoperative drug costs & $\$ 25.72$ & $\$ 17.27$ & $-\$ 8.45(-\$ 15.96$ to $-\$ 0.94)$ \\
All patients & $\$ 3.50$ & $\$ 2.90$ & $-\$ 0.59(-\$ 1.83$ to $\$ 0.64)$ \\
$\quad$ Antiemetics & $\$ 21.90$ & $\$ 14.48$ & $-\$ 7.41(-\$ 14.49$ to $-\$ 0.34)$ \\
$\quad$ Analgesics & $\$ 37.27$ & $\$ 21.06$ & $-\$ 16.22(-\$ 31.09$ to $-\$ 1.34)$ \\
Laparoscopic cholecystectomy & $\$ 17.55$ & $\$ 13.79$ & $-\$ 3.78(-\$ 9.87$ to $\$ 2.35)$ \\
Laparoscopic tubal ligation & & & $-\$ 10.03(-\$ 19.82$ to $-\$ 0.23)$ \\
Total drug costs & $\$ 56.81$ & $\$ 46.78$ & $-\$ 22.94(-\$ 39.25$ to $-\$ 6.64)$ \\
All patients & $\$ 81.06$ & $\$ 58.13$ & $-\$ 2.87(-\$ 10.07$ to $\$ 4.34)$ \\
Laparoscopic cholecystectomy & $\$ 39.22$ & $\$ 36.35$ & \\
Laparoscopic tubal ligation & &
\end{tabular}

* Note that $95 \%$ confidence intervals $(\mathrm{CI})$ are reported but $P<0.001$ is considered statistically significant due to the multiple comparisons. $\dagger P<0.001$. $\ddagger$ Remifentanil in the sevoflurane group; fentanyl in the propofol group.

\section{Discussion}

We did not find a statistically significant difference in 24-hr moderate to severe PONV between sevoflurane-remifentanil induction and propofol induction. Our sample size had $84 \%$ power to detect an absolute difference of $16.5 \%$, seen in this study, and $90 \%$ power to detect an absolute difference of $25.6 \%$ with a type I error rate of $5 \%$. Given our findings, we would have required 198 patients to achieve statistical significance with $90 \%$ power.

In terms of secondary clinical outcomes, there were no differences in 24-hr moderate to severe postoperative pain, intubating conditions, induction and emergence times, and time to achieve fast-track discharge criteria. These findings were consistent with the subjective impressions of the anesthesiologists and the blinded postoperative caregivers. Previous concerns with potential delays in endotracheal intubations using sevoflurane induction did not seem to be a problem in this study with the use of remifentanil. A post-trial survey of the individuals involved with the clinical care of the patients showed that $80 \%(28 / 35)$ felt there was no subjective difference between the two groups in terms of PONV or postoperative pain.

In terms of secondary pharmacoeconomic outcomes, patients in the sevoflurane group received an extra $3 \mathrm{mg}$ of $i v$ morphine postoperatively. Although the difference was statistically significant, we are doubtful of its clinical or economical (\$0.05) significance.
Compared to the propofol group, we did not find any statistically significant difference in intraoperative anesthetic drug costs, postoperative drug costs, or total 24hr drug costs for all patients in the sevoflurane group. A trend towards increased postoperative drug costs and total 24-hr drug costs in patients undergoing laparoscopic cholecystectomy was seen in the sevoflurane group. In contrast, lower intraoperative drug costs ${ }^{29,30}$ and perioperative $\operatorname{costs}^{30}$ with sevoflurane induction were reported in previous clinical trials comparing sevoflurane and propofol induction. Different surgical procedures may explain the differences between our results and those of previous trials.

In this study, we did not detect a difference in costs, clinical outcome, anesthetic time, and recovery time between the two induction techniques. We suggest that more research in the pharmaco-economics $v s$ clinical outcome in various outpatient surgical populations is necessary. It is worth noting that with the use of prophylactic anti-emetics, such as ondansetron, the sample size required would be significantly larger in order to study the clinical and economical trends observed in this study. For example, if we assume an event rate of $20 \%$ with the use of prophylactic ondansetron and propofol induction (based on 36.7\% risk of PONV in this study and an absolute risk reduction of $16.7 \%$ with prophylactic ondansetron), ${ }^{31}$ we would need 308 subjects to detect an absolute difference of $16.5 \%$ (based on $53.2 \%$ risk of PONV in this 
study and an absolute risk reduction of $16.7 \%$ with prophylactic ondansetron $)^{31}$ between sevoflurane and propofol induction with 5\% type I error rate and 90\% power. Most studies are underpowered to detect such a difference.

In summary, compared to propofol-fentanylrocuronium induction, sevoflurane-remifentanil induction was a clinically feasible technique for laparoscopic cholecystectomy and laparoscopic tubal ligation without causing a statistically significant difference in 24-hr moderate to severe PONV. We did not find any clinically significant differences in secondary outcomes, induction time, emergence time, recovery time, or costs.

\section{Acknowledgements}

We thank Helen Jan, RN, Shirley Than, RN, and Kristine Wilson-Yang, PhD for their assistance in data collection; Alison van Nie, MA for coordinating the study and for constructive criticisms of early drafts of this paper, and the anesthesiologists, nurses, and patients at the Hamilton Health Sciences and St. Joseph's Healthcare Hamilton for their participation in this study.

\section{References}

1 Watcha MF, White PF. Postoperative nausea and vomiting. Its etiology, treatment, and prevention.

Anesthesiology 1992; 77: 162-84.

2 Hedayati B, Fear S. Hospital admission after day-case gynaecological laparoscopy. Br J Anaesth 1999; 83: 776-9.

3 Chung F, Mezei G. Adverse outcomes in ambulatory anesthesia. Can J Anesth 1999; 46(5 Pt II): R18-34.

4 Tong D, Chung F, Wong D. Predictive factors in global and anesthesia satisfaction in ambulatory surgical patients. Anesthesiology 1997; 87: 856-64.

5 Haigh CG, Kaplan LA, Durham JM, Dupeyron JP, Harmer M, Kenny GN. Nausea and vomiting after gynaecological surgery: a meta-analysis of factors affecting their incidence. Br J Anaesth 1993; 71: 517-22.

6 Naguib M, El Bakry AK, Khoshim MH, et al. Prophylactic antiemetic therapy with ondansetron, tropisetron, granisetron and metoclopramide in patients undergoing laparoscopic cholecystectomy: a randomized, double-blind comparison with placebo. Can J Anaesth 1996; 43: 226-31.

7 Jokela $R$, Koivuranta $M$. Tropisetron or droperidol in the prevention of postoperative nausea and vomiting. A comparative, randomised, double-blind study in women undergoing laparoscopic cholecystectomy. Acta Anaesthesiol Scand 1999; 43: 645-50.
8 Juckenhofel S, Feisel C, Schmitt HJ, Biedler A. TIVA with propofol-remifentanil or balanced anesthesia with sevoflurane-fentanyl in laparoscopic operations. Hemodynamics, awakening and adverse events (German). Anaesthesist 1999; 48: 807-12.

9 Swiatkowski J, Goral A, Dzieciuch JA, Przesmycki K. Assessment of ondansetron and droperidol for the prevention of post-operative nausea and vomiting after cholecystectomy and minor gynaecological surgery performed by laparoscopy. Eur J Anaesthesiol 1999; 16: 766-72.

10 Divatia JV, Vaidya JS, Badwe RA, Hawaldar RW. Omission of nitrous oxide during anesthesia reduces the incidence of postoperative nausea and vomiting. A meta-analysis. Anesthesiology 1996; 85: 1055-62.

11 Hartung J. Twenty-four of twenty-seven studies show a greater incidence of emesis associated with nitrous oxide than with alternative anesthetics. Anesth Analg 1996; 83: 114-6.

12 Tramèr M, Moore A, McQuay H. Omitting nitrous oxide in general anaesthesia: meta-analysis of intraoperative awareness and postoperative emesis in randomized controlled trials. Br J Anaesth 1996; 76: 186-93.

13 Tramèr M, Moore A, McQuay H. Meta-analytic comparison of prophylactic antiemetic efficacy for postoperative nausea and vomiting: propofol anaesthesia vs omitting nitrous oxide vs total i.v. anaesthesia with propofol. Br J Anaesth 1997; 78: 256-9.

14 Tramèr M, Moore A, McQuay H. Propofol anaesthesia and postoperative nausea and vomiting: quantitative systematic review of randomized controlled studies. Br J Anaesth 1997; 78: 247-55.

15 Sneyd JR, Carr A, Byrom WD, Bilski AJ. A meta-analysis of nausea and vomiting following maintenance of anaesthesia with propofol or inhalational agents. Eur J Anaesthesiol 1998; 15: 433-45.

16 Joo HS, Perks WJ. Sevoflurane versus propofol for anesthetic induction: a meta-analysis. Anesth Analg 2000; 91: 213-9.

17 Tramèr MR, Fuchs-Buder T. Omitting antagonism of neuromuscular block: effect on postoperative nausea and vomiting and risk of residual paralysis. A systematic review. Br J Anaesth 1999; 82: 379-86.

18 Alexander R, Booth J, Olufolabi AJ, El-Moalem HE, Glass PS. Comparison of remifentanil with alfentanil or suxamethonium following propofol anaesthesia for tracheal intubation. Anaesthesia 1999; 54: 1032-6.

19 Alexander R, Olufolabi AJ, Booth J, El-Moalem HE, Glass PS. Dosing study of remifentanil and propofol for tracheal intubation without the use of muscle relaxants. Anaesthesia 1999; 54: 1037-40.

20 Grant S, Noble S, Woods A, Murdoch J, Davidson A. Assessment of intubating conditions in adults after 
induction with propofol and varying doses of remifentanil. Br J Anaesth 1998; 81: 540-3.

21 Klemola UM, Mennander S, Saarnivaara L. Tracheal intubation without the use of muscle relaxants: remifentanil or alfentanil in combination with propofol. Acta Anaesthesiol Scand 2000; 44: 465-9.

22 Stevens JB, Wheatley $L$. Tracheal intubation in ambulatory surgery patients: using remifentanil and propofol without muscle relaxants. Anesth Analg 1998; 86: $45-9$.

23 Thompson JP, Hall AP, Russell J, Cagney B, Rowbotham $D J$. Effect of remifentanil on the haemodynamic response to orotracheal intubation. Br J Anaesth 1998; 80: 467-9.

24 Woods AW, Grant S, Harten J, Noble JS, Davidson JA. Tracheal intubating conditions after induction with propofol, remifentanil and lignocaine. Eur J Anaesthesiol 1998; 15: 714-8.

25 Joo HS, Perks WJ, Belo SE. Sevoflurane with remifentanil allows rapid tracheal intubation without neuromuscular blocking agents. Can J Anesth 2001; 48: 646-50.

26 Peterson RG. Cardiovascular toxicity with injectable droperidol (Letter). Therapeutics Products Directorate, Health Canada; 2002 February 12.

27 White PF, Song D. New criteria for fast-tracking after outpatient anesthesia: a comparison with the modified Aldrete's scoring system. Anesth Analg 1999; 88: 1069-72.

28 Apfel CC, Lä̈̈rä E, Koivuranta M, Greim CA, Roewer $N$. A simplified risk score for predicting postoperative nausea and vomiting. Conclusions from cross-validations between two centers. Anesthesiology 1999; 91: 693-700.

29 Fleischmann E, Akca O, Wallace T, et al. Onset time, recovery duration, and drug cost with four different methods of inducing general anesthesia. Anesth Analg 1999; 88: 930-5.

30 Tang J, Chen L, White PF, et al. Recovery profile, costs, and patient satisfaction with propofol and sevoflurane for fast-track office-based anesthesia. Anesthesiology 1999; 91: 253-61.

31 Tramèr MR. Systematic reviews in PONV therapy. In: Tramèr $M(E d$.$) . Evidence Based Resource in$ Anaesthesia and Analgesia. London: BMJ Books; 2000: 157-78.

32 Viby-Mogensen J, Engbaek J, Eriksson LI, et al. Good clinical research practice (GCRP) in pharmacodynamic studies of neuromuscular blocking agents. Acta Anaesthesiol Scand 1996; 40: 59-74. 